\section{INDEX TO ADVERTISERS}

Batelle Marine Sciences Operations

Belfort Instruments

Biral

Campbell Scientific

Coastal Environmental Systems, Inc.

Department of Energy - ARM

Distromet Ltd.

Environmental Research Services

Geonor Inc.

Global Science \& Technology, Inc.

Harvard University

IPS MeteoStar, Inc.

John Wiley and Sons Ltd

Kipp \& Zonen (USA) Inc.

LI-COR Biosciences

Massachusetts Institute of Technology

MFG Galileo

NOAA Direct Readout Conference

Northrop Grumman

R. M. Young Company

SGT, Inc.

Textron Systems

Yankee Environmental Systems, Inc.

AMS Publications, Preprints, etc. 10th AMS Student Conference and Career Fair

1587

AMS 2011 Washington Forum

AMS Books

AMS Career Fair

1588

1545

1524

1601

1564

1523

1491

1603

1589

1492

\section{ONLINE CAREER CENTER}

The AMS Online Career Center may be accessed through the AMS Web site at www.ametsoc.org/careercenter/index.html. In addition to posting positions, advertisers may search and view job seekers' résumés.

\section{Job Posting Rates:}

\$375 (30-day posting)

$\$ 1593.75$ (5 pack of jobs) Usable for 30-day job postings. Buy 5 job posting credits at a $15 \%$ discounted rate. These credits may be used at anytime during the next 12 months.

$\$ 3000$ (10 pack of jobs) Usable for 30 -day job postings. Buy 10 job-posting credits at a $20 \%$ discounted rate. These credits may be used at anytime during the next 12 months.

\$3375 (12 pack of jobs) Usable for 30-day job postings or a continual 12-month posting. Buy 12 job-posting credits at a $25 \%$ discounted rate. These credits may be used at anytime during the next 12 months.

Advertisers may upload a company logo free of charge.

RÉsumÉs: View complete resumes for free! If you find any candidates you are interested in, submit your interest to them. If the candidate is interested in your opportunity, we connect you for just $\$ 20.00$. If the candidate is not interested, you pay nothing!

AMS Corporation Member Discounts: Active AMS Corporation Members (small business, regular, or sustaining) receive a $25 \%$ discount when posting a position. Contact Kelly G. Savoie (ksavoie@ametsoc.org) to receive a coupon code. To receive the discount, the code must be entered when you post a position. The discount code is non-transferable.

AMS Member Benefit: AMS Members will be given 14days advance access to a job listing. A member-only symbol will appear next to the posting. After 14 days, the job posting is open to all.

Submission of Ads: Advertisers must create an online account and submit ad text through the AMS Career Center site. Ad text may be entered at any time.

Payment Information: Prepayment is required by credit card or valid purchase order.

CONTACT INFORMATION: If you have questions, please contact Customer Service at 888-575-WORK (9675) (inside U.S.) or 860-440-0635 (outside U.S.).

\title{
ADVERTISING POLICY
}

The AMS will accept tastefuland accurate advertisements for products and services of professional interest to AMS members from organizations that are actively involved in the atmospheric and related sciences. The AMS also accepts advertising from organizations that have an interest in the atmospheric and related sciences and services, but are not actively involved in them. These organizations may promote their contributions to AMS activities and other good works, but may not directly promote products or services. The AMS reserves the right to refuse advertising that does not meet these criteria. Acceptance of advertising does not constitute the Society's endorsement of the product or service being advertised. 